\title{
Entrevista com Andrew Hardwood e Ray Chung
}

\section{Suzi Weber* Tradução: Cláudia Müller Sachs**}

Resumo

Entrevista realizada em Montréal em 2006, com os bailarinos, improvisadores e performers norte-americanos Andrew de Lotbinière Harwood e Ray Chung por ocasião da performance Hark. Em Hark, a improvisação em dança é crucial e o contato improvisação é um dos principais ingredientes. Nesta entrevista, feita antes da performance, eles falam de sua formação, prática, abordagem pedagógica e compreensão da arte, da dança e da performance. A influência do Contato Improvisação amalgamada com a educação somática demonstra a forte aliança da prática em dança destes artistas que tem permitido sua longevidade em cena. Além disso, essa aliança tem promovido uma minimização de gestuais hierarquizados e virtuosos de dança ligados à superação física do corpo, oferecendo corpos mais relaxados, performáticos e até vulneráveis. Para estes artistas, a percepção e atenção do público estão em evidência no momento da criação.
Abstract

Interview held in Montreal in 2006, with the dancers, improvisers and performers Andrew Lotbinière Harwood and Ray Chung from North America by the time of the performance "Hark". In this performance, improvisation in dance and contact improvisation are crucial. In this interview, done before the performance, they talk about their background, their practice, pedagogical approach and understanding of art, dance and performance. The influence of Contact Improvisation fused with somatics demonstrates the strong bond of the practice of these dance artists which has allowed their longevity on stage. Moreover, this alliance has pomoted a minimization of hierarchical and virtuos gestural dance linked to a physical overcoming of the body, offering more relaxed, performatic and even vulnerable bodies. For these artists, the perception and attention of the public are in evidence at the time of creation. 
Suzi Weber - Quais são as técnicas de movimento que fazem parte de sua experiência, de maneira indireta ou direta, que vocês integraram na experiência do contato improvisação? O que vocês integraram nas aulas e nas performances?

RC - Minha expediência com as artes marciais, particularmente o judô e o Tai Chi. E também minha experiência com trabalho de corpo, particularmente o Shiatsu, realmente me informaram sobre como interagir com outros corpos. E também diferentes experiências com dança foram se acumulando como camadas sobre aquelas outras, e depois muito contato improvisação nessa mistura, misturando tudo isso junto. Mas sinto que foi importante eu estar aprendendo trabalho de corpo e contato ao mesmo tempo, porque acredito que eles realmente se instruíam um ao outro... Para mim, o trabalho de corpo é como o contato improvisação. Se estou realmente conectado, eu posso improvisar e não preciso trabalhar com um determinado padrão de trabalho, pois estou realmente escutando. Posso enfocar somente numa área e isso vai afetar a coisa toda, muito parecido com dançar. Quero dizer, antes do contato, fiz um pouco de dança Afro e gostava muito, mas não gostava muito da maneira como era ensinada. E agora, dancei com tantos bailarinos e aprendi um pouco com cada um. Então é realmente interessante aprender dança dessa maneira, ao invés de fazer muitas aulas. $E$, continuando, é um processo contínuo que, eu espero, bem, eu tenho certeza, não cessará.

AH - Estou curioso se... Eu sei, ou acho que sei, que você segue pessoas como Ann Halprin, como outras pessoas que não realizam trabalho de contato, mas pessoas que tiveram um interesse paralelo em improvisação, e de alguma forma conectaram-se com o trabalho. Então, não sei se há algumas dessas pessoas que...

RC - Sim, eu senti vontade. Fiquei longos períodos com Ann, mas achei que o que eu realmente gostava era como ela trabalhava com grandes grupos de pessoas. E sim, peguei muito daquilo, que me ajuda a trabalhar com grupos grandes, algo que acabo fazendo bastante, embora não seja o meu favorito.

Suzi Weber - Porque há as técnicas de movimentos, mas há também a experiência com as pessoas que também fazem a formação.

$\mathrm{AH}$ - Sim. É isto que ele disse. Exatamente. Apenas reiterando que não é apenas estudar formas, mas o trabalho com pessoas. Serve como uma maneira, como você disse, de aprender, interagir e colaborar com pessoas. E você realmente aprende isso a cada vez que trabalha com alguém, sabe, é uma experiência de aprendizado também, que você integra ao processo como um todo.

RC - E acho que, hoje em dia, meu interesse é menos em formas de movimentos, pelo menos no meu tipo de pesquisa. Mas mais conceitualmente. Tenho lido bastante semiótica, que é estudo de ciência e de como as coisas têm sentido. E da linguagem para a mística, a dança, e como elas se relacionam com comunicação. Porque para mim, frequentemente, dança trata de 
comunicar algo. Arte, em geral. Então se algo faz sentido para mim, ou se não faz, tenho curiosidade sobre como, qual o processo? Porque sinto que pode me informar, como eu crio algo.

$\mathrm{AH}$ - Faz sentido! (risos) Faz sentido! (risos) Vamos ver, meu background em movimento. Bem, se eu voltar para o começo, realmente, minha primeira experiência em movimento foi duas coisas. Uma delas foi esportes de equipe e atletismo. Eu fiz muitos esportes de equipe e muito atletismo quando eu era jovem. E, em seguida, um pouco mais tarde, ginástica. E essas três coisas tiveram, e ainda conservam, para mim, elementos importantes que eu sinto que ainda incorporo em aula, e isso é um elemento de jogo, os jogos, para ter algum tipo de estrutura com a qual você está trabalhando, mas que você também está improvisando. Assim, os esportes de equipe proporcionam a sensação de trabalhar com outros, de tentar reunir seus recursos num conjunto, as suas energias, seu Eu físico e mental, e juntos focarem-se num objetivo comum. E eu gosto muito disso, gosto da camaradagem e da interação. Atletismo e ginástica são mais uma espécie de, especialmente de ginástica, evento solo. Você não faz ginástica com outras pessoas em si, você faz sozinho, e você compete contra outras pessoas que fazem rotinas individuais. Mas, há algo sobre a disciplina daquilo, o rigor, a precisão das coisas, que eu realmente gostei, e a concentração. Era muito exigente, fisicamente, mas também muito emocionante. $E$ foi lá que eu fiquei muito familiarizado com o que eu chamaria de movimento tridimensional: ficar de cabeça para baixo, fazer todos os tipos de saltos e giros no ar, saltar para trás. Então, quando eu vim para contato improvisação, quando comecei a fazer contato, aquilo me era familiar, não era como "Ôh, uau, eu me sinto completamente desorientado".Meu corpo conhecia aquilo. Meu corpo sabia como fazer aquilo. Eu podia fazer paradas de mão, eu podia fazer saltos, eu podia fazer todos os tipos de coisas, de anos de treinamento. Então, isso já estava construído em mim. Em seguida, um pouco mais tarde, o ioga tornou-se um interesse muito forte para mim, que eu ainda incorporo em aula, em aquecimentos, e meditação. Então, aquela idéia de canalizar a sua energia a partir de dentro, com foco, eu realmente gostava muito. $E$... vamos ver, tudo isso me trouxe para a dança. $E$ eu estudei dança moderna por dois anos. Técnica de Graham e improvisação, não contato. Algo mais geral. Apenas improvisação, trabalhando com grandes grupos de pessoas. $E$, em seguida, entrou o contato. E o contato me abriu portas para muitas outras coisas. A técnica de Alexander, que é o interesse no trabalho de alinhamento, o interesse na postura. A técnica de Release, que foi liberando o excesso de tensão, holding, então havia eficiência em seu movimento. Todas essas coisas eu tentei incorporar nas minhas aulas. Então, elas estão todas lá, pego pedaços de informação e junto a partir dessas informações, e tento apresentar isso em aula, de uma forma que seja ao mesmo tempo divertida, profunda e significativa para as pessoas e que as ajude a conseguirem conectar-se a si mesmas e com outras pessoas, de maneiras realmente profundas. Então, todas essas disciplinas têm sido muito úteis para mim, e eu recorro a tudo isso. E eu improviso com muitas pessoas há 30 anos ... Eu fiz bastante improvisação com pessoas diferentes, e a arte 
marcial que eu estudei foi Aikido, esqueci de mencionar isso. Mais ou menos naquela época, quando eu comecei a dançar, meus primeiros dois anos, estudei Aikido seriamente por cerca de cinco anos. E todas aquelas disciplinas ou técnicas, eu acho, bem como, eu diria, provavelmente o mesmo para Ray, podemos recorrer a essa informação, e usá-las de maneira que parecem apropriadas, em aula. E eu acho também que, como disse Ray, a interação com muitas pessoas diferentes, ao longo de muitos e muitos anos, sabe, eu aprendo com cada pessoa com quem eu trabalho. Realmente. É um processo contínuo. Eu ainda sinto que estou aprendendo. Mas depois, sabe, trinta, quarenta anos que eu tenho estado muito envolvido com movimento, eu não faço muito mais aula. Minha maneira de aprender é através do fazer, da performance, é por meio do ensino e através da colaboração com outras pessoas. Você sabe, passar tempo com as pessoas com quem estou trabalhando é tão importante quanto estar em sala dançando, ensaiando, trabalhando duro, conceituando nosso dialogar. Apenas o tempo que você gasta para conhecer alguém... Como, por exemplo, Ray está aqui por dez dias e nós estamos saindo, passamos tempo juntos. E mesmo sendo assim relaxado, descontraído, amigável, para mim é importante. É aí que você consegue fazer outros tipos de conexões que você não faz no estúdio. O que percorre um longo caminho de abertura de portas sutis e cria certo tipo de conexões. De alguma forma, quando você está no estúdio sua energia está focada de uma maneira diferente. $\mathrm{E}$ assim, aqueles tipos de coisas podem não emergir. Embora Ray e eu temos trabalhado juntos há muito tempo, normalmente o tempo no estúdio é bastante descontraído e muito agradável, e eu diria que bastante produtivo. Ir para o estúdio para trabalhar ou ensaiar às vezes não é tão diferente do que fazer a performance. É interessante, sabe. O mesmo tipo de foco, atenção e compromisso poderia ser encontrado no estúdio com apenas nós dois, sem mais ninguém na sala e entrar em um estado muito profundo, que é muito semelhante à performance, sem ninguém ao redor. $E$ isso é apenas a maneira de se concentrar e se divertir. Então ... cada vez que vamos para o estúdio para ensaiar ... Ensaiar em estúdio e fazer a performance não é muito diferente. O que traz mudanças no contexto é o fato de que há um grande número de pessoas que vêm ver o que fazemos. $E$ isso acentua muito as coisas, e certamente faz outras coisas surgirem. Mas em termos de foco, eu não sinto que eu preciso de alguém para dirigir o ensaio, e me dizer o que fazer, me dizer como se concentrar para que eu possa alcançar aquele estado, e ser criativo e mergulhar profundamente em nosso processo de ensaio, e tornar aquilo agradável ao mesmo tempo. Então ...

Suzi Weber - E você falou que fazer cursos, estágios e o processo de representação, as fronteiras não são muito rígidas, fixas.

$\mathrm{AH}$ - Sim, é isso. Bem, aula... aula é diferente para mim, do que ensaio e performance. Não é que, para mim, haja uma mudança. Eu desenho uma linha lá. Não é a mesma experiência, para mim pessoalmente, como um ensaio. Ensaio está perto de performance. Ou sentar, falar sobre a performance que fizemos ontem, ouvir música, ter algumas idéias, brainstorming, conceituar 
um pouco, para mim tudo isso vai na mente da performance criativa; é suco. Ensinar, para mim, é outra coisa. É uma arena onde há, é claro, conhecimento sendo compartilhado, e dado, e compartilhado. Mas é realmente dividido, em sala de aula. Você sabe, é muito "stop and go" (pára e anda). Estamos trabaIhando muito especificamente, às vezes, em certas coisas.

Muito especificamente. As técnicas que ensinamos são específicas. Nós entramos em detalhes.

Quando estamos ensaiando, você sabe, nós estamos indo para outros tipos de detalhes, e é mais detalhes sobre estados de ser, e performance, e imaginação, e imagens, e foco. Que é diferente do que trabalhar no compartilhamento do peso ou no jogar os nossos corpos nos outros. Nós sabemos como fazer. Nós fizemos isso por tanto tempo. Portanto, não é bem a mesma coisa. Sim ... É diferente para mim.

Suzi Weber - Você falou sobre técnicas do corpo. Aquilo que denomino Educação Somática é um grande guarda-chuva - as técnicas de Alexander, o Body Mind Centering, Trabalho de corpo, essas são técnicas de educação do movimento que eu considero. Você poderia falar um pouco sobre essas técnicas de educação do movimento, se você as considera importantes? Em todas as suas referências de técnicas de movimento, especificamente, essas técnicas de movimento, de educação do movimento? E o que vocês entendem que faz diferença?

RC - Sim, faz diferença porque muda o seu ponto de referência ou o seu quadro de diferença, e como você vê o seu corpo, e os corpos dos outros. Porque a maioria das pessoas, elas criam a sua realidade, elas estão criando o seu corpo em um certo sentido. Porque elas têm essa imagem de quem elas são, e como se movem no mundo. $E$, muitas vezes, em minhas aulas, eu gosto de afetar sua auto-imagem como parte do trabalho. De modo que, se eu puder incutir confiança de que podem fazer qualquer coisa, então é menos trabalho para elas tentarem algo novo. Na minha experiência eu me deparei como BMC, Feldenkrais, artes marciais, outros trabalhos de corpo, que me informam sobre como perceber o meu próprio corpo, para que eu possa articular como ajudar alguém a perceber seu corpo daquela certa maneira, de modo que elas possam ir um pouco além do que eles estão normalmente acostumadas, ou dispostas a fazer. E por muitos anos, eu nunca demonstrava em minhas aulas, porque eu procurava apenas levar as pessoas através da fala e fazê-las tentar por conta própria, de modo que seu corpo iria fazê-lo da maneira que seu achasse necessária. Mas depois de um tempo, eu descobri, sabe, viajando por lugares diferentes que as pessoas querem ... ou, pelo menos, como eles aprendem a aprender. Eles requerem um determinado tipo de informação, como a forma de fazer aquilo, de uma certa maneira. Então, eu acabei acrescentando isso e depois, mais recentemente, tornou-se na verdade uma espécie de técnica. Porque as pessoas adoram técnica! (risos) Porque eles sentem que aquilo é realmente a carne, o cerne da coisa. E para mim, é uma parte importante, mas não é a coisa toda. Ele ainda é uma espécie de tentativa de descobrir "Ok , quais são as peças que faltam no processo 
", e ... é um processo contínuo. Para mim, também. E o aprendizado sobre isso.

$\mathrm{AH}$ - É. Vou apenas acrescentar que Ray tocou nisso em uma de suas aulas esta semana, e no fim de semana, só de pensar em estudos de somática, ou princípios do movimento, e como você encontra esses princípios de muitas maneiras. Os mesmos princípios, essencialmente. O que é interessante sobre os estudos somáticos como Body Mind Centering, ou trabalho de alinhamento, ou técnica de release, é que eles estiveram em um estudo aprofundado desta avenida em particular, e como expressar alguns desses princípios de maneiras que são muito particulares àquela abordagem. Por exemplo, na técnica de release, eles usam muitas imagens para conectar, para ajudar as pessoas a se conectarem com algo que ... Eles possam usar para ajudá-las a se transformarem ou compreender. E assim, torna-se um outro bloco de construção. Assim como a demonstração pode se tornar uma grande ferramenta, como quando as pessoas vêem. Eu gosto de demonstrar muito em sala de aula . E usei quase sempre ao longo dos anos, e eu sempre achei que as pessoas, quando você lhes dá uma imagem com a qual trabalhar, muitas vezes apagam-se muitas perguntas, de modo que todas as perguntas que possam surgir de não demonstrar de alguma forma podem ser resolvidas. E a idéia de demonstrar não é para as pessoas fazerem ou repetirem o que eu demonstro. Mas é simplesmente colocá-los na pista certa. É como "esta é a direção", e então muitas vezes eu adiciono a isso "não tente fazer o que eu fiz, mas encontre a maneira que funciona para você hoje, em seu corpo, e dada a forma como você está se sentindo, com quem está trabalhando". E, todos aqueles parâmetros que acabei de descrever, em que poucas coisas podem mudar muito de dia para dia. Como está se sentindo, com quem você está trabaIhando, todas essas conexões psicológicas que você tem, o material emocional que vem com ele também. Então ... Sim, trabalhar com princípios do movimento é realmente importante. E estudar as diferentes abordagens Ihe dá mais com o quê trabalhar. Porque, como disse Ray, é tudo sobre comunicação, e como professores, nós somos comunicadores também. Como artistas, nós somos comunicadores, como artistas da dança, somos comunicadores, bem como para uma audiência, e um para o outro. Minha primeira professora contato não foi Nancy, foi na verdade Nita Little, que, em 1975 quando eu fiz uma aula com ela, ela dizia que "Contato Improvisação é a arte de prestar atenção, a arte da atenção, de estar atento". Então, qualquer que seja o meio que você utilize para incitar a atenção das pessoas e levá-los a ter um ... incutir-lhes um verdadeiro sentimento de descoberta, de querer descobrir, ao contrário de "Oh , eu sei tudo". Então, você muda essa premissa de "Eu sei que as coisas", e a substitui pelo sentido de "Uau, é maravilhoso descobrir uma nova forma de fazer alguma coisa." Pode ser algo que você já tenha feito mil vezes antes. E justamente por causa da maneira como você pensa sobre isso, ou o reaplica, isto pode ser sentido completamente diferente. Ou você traz alguma outra noção do Body Mind Centering, ou do trabalho de Alexander, ou Kung Fu, ou Tai Chi, ou algo assim, sabe, isso é relativo e ... Por causa do background das pessoas, ele pode pensar" Aha ! Eu me identifico 
com isso!" Assim, quanto mais você tem disso , eu acho, aquele caleidoscópio de linguagem, experiência, e meios de comunicá-lo, eu acho que facilita o aprendizado, assim como, para as pessoas que estão do outro lado, recebê-lo.

Suzi Weber - (...) Eu gostaria de fazer uma pergunta sobre a performance de sexta-feira. Para essa performance, o que vocês prepararam ou pensaram? Vocês fizeram em casa, fizeram desenhos, esquemas? Como você me disse, vocês trabalharam mais aqui, não trabalharam num estúdio ...Eu gostaria de saber se é por vocês ficarem quase vinte e quatro horas por dia juntos, se é essa intimidade pode ajudar também? Como, para a performance?

RC - Eu me sinto como se tivéssemos recém começado, quero dizer, o processo formal em si. Mas, para mim, tudo começou mesmo antes de eu chegar, com um e-mail, ou algo no ar em minha psique de fazer uma performance, "Oh, com Andrew , oh, Ok!"

$\mathrm{AH}$ - " Em Montreal. Minha primeira vez! Oh , wow!

RC - E então minha imaginação está acionada, e isso começa a mexer com muitas coisas. Então, isso é mais ou menos onde o processo começou para mim. E apenas um pensamento sobre isso, e...

$\mathrm{AH}$ - Sim, como uma semente que é largada. Vamos fazer alguma coisa. ( Faz o gesto de plantar uma semente) Aqui e ali. Assim como a semente, às vezes, gosta, fica e começa a se desenvolver.

RC - E então, pelo que eu sei, e da experiência de realização de performances, e com Andrew, sinto que temos um monte de coisas com as quais poderíamos trabalhar, sem sequer ter de dizer "Oh, nós precisamos inventar alguma coisa." Porque, sim, eu tenho muita confiança na sua experiência e capacidade de fazer a coisa certa.

$\mathrm{AH}$ - E para fazer alguma coisa.

RC - É. Bem, para fazer o que for preciso, quero dizer.

$R C$ - $E$ muitas vezes eu sinto que isso é o suficiente, mas há também uma parte de mim, eu acho, uma parte da minha mente que quer saber, e precisa de controle, quer entrar com um pouco mais de estrutura, algo que seja um pouco mais definido e sabido. E para mim esse é o desafio! O tipo de criação antes do evento em si. Porque, muitas vezes, no momento em si, se eu estourealmente presente, eu sinto que, "ok, ele simplesmente se desdobra para mim." Porque, você é o corpo vivo, eu sou o corpo vivo, nós podemos começar a interagir com o espaço, o público, a música, seja o que for. E então, está tudo lá. Mas, para criar quando não estou lá, quando não estou presente na situação real, ou aquela não é a realidade atual, às vezes é mais difícil para mim.

$\mathrm{AH}-\mathrm{E}$... Eu acho que Ray tocou nisso antes, quando ele disse que um contexto com o qual ele é muito confortável é quando ele é aberto, sabe, quando a performance é deixada em aberto. E eu seguido trabalho dessa maneira também com muitas pessoas, quando muito pouco é decidido, sabe. Ou nada. Realmente, nada mesmo. Nós ensaiamos em nossos ensaios; nós só improvisamos, nós falamos sobre isso, nossas conexões, nossa dança, e 
como nos sentimos, ou o que quer que seja. E então, isso torna-se o processo de ensaio, estamos apenas improvisando, e levamos isso para a performance. Estou muito confortável com isso também. Dito isto, eu também gosto de trabalhar, às vezes, com algum tipo de conceito de antemão. Algo que não só vai apoiar a improvisação, mas dar-lhe um sabor de algum tipo.

Apenas algo que possa ser de interesse para mim mais tarde. Certamente visual, o visual no espaço, ou algo que seja muito ... Não é que eles sejam importantes, mas eles me afetam, de uma forma grande. Luzes afetam, música ou não, música ao vivo, música gravada, sabe, se há objetos no espaço, se há vídeo ou não. Eu estou interessado em tudo isso, e muito curioso e interessado em um ambiente muito rico onde vou fazer a performance. $E$ isto poderia ser muito muito rico, ou poderia ser muito simples. Não precisa muito para criar um ambiente muito rico. Na verdade, você pode criar um ambiente muito rico com nada. Não é que temos que ter essas coisas, é só que ... é um pouco diferente, às vezes ,ir naquela direção. E assim, ele suscita diferentes coisas. Então, juntando as porcas e os parafusos em termos de como nos preparamos para isso, como Ray disse, acho que há uma primeira semente que é plantada, e há um desejo, em primeiro lugar. E há um " Ah , ok , vamos fazer alguma coisa", e assim, isso cria um contexto. Onde, quando? Se for em um festival, se é em um estúdio, se há outras pessoas, se nunca estive lá antes, ou já tinha estado lá antes, "Oh, sim, é em Nova York, festival de Improvisação, isto é familiar". Ao contrário de que se não é familiar. Nós dois estivemos na Itália para uma performance, sabe, e nós nunca tínhamos ido a este festival antes, e isto criou um contexto, e havia outras pessoas ... Aqui, é diferente, apenas nós dois, é muito íntimo, não há mais gente ao redor. Nós lidamos com as restrições da performance também. Não tivemos muito tempo de ensaio em um estúdio neste final de semana, mas Ray está dando muitas aulas, eu estou fazendo aula, nós passamos tempo juntos, e isso, para mim, é como eu disse anteriormente, é muito valioso também.

Mas uma das coisas que nós dois falamos sobre a preparação para esta performance é apenas música. Eu não tinha dinheiro suficiente para contratar músico neste projeto, que eu quase sempre faço. Eu, sempre prefiro ter música ao vivo. Eu gosto da interação com os músicos ao vivo. E eu gosto muito mais do que os trabalhos de improvisação com música composta, pré-gravada. Dito isto, há milhares de pré-gravadas que eu amo, que realmente me movem, me estimulam, me inspiram. Então, nós passamos ontem algum tempo ouvindo música, e trazendo algumas músicas diferentes que nós gostamos de usar. Nós falamos sobre o espaço, e talvez, como usá-lo . Sabe, alguns adereços simples ou objetos que poderíamos trazer. $\mathrm{E}$, basicamente, isso é até onde vamos, é o que temos. Acho que não vamos planejar muito, vamos deixá-la bastante aberta. Mas você sabe, há questões e problemas que vêm com a utilização de música gravada. E então, discutimos se nós vamos controlar isso e sermos responsáveis pela música, ou deixar alguém fazer isso, ou, tomar todas essas decisões. Quem vai colocar a música, e tirá-la? Quem vai tomar essa decisão? Será nossa responsabilidade ou vamos pedir a alguém para 
fazê-lo, dar-lhe a responsabilidade. Então, esses são os tipos de questões quesurgiram. Mas você sabe, Ray e eu podemos muito facilmente, como fizemos na Itália, não ter nada preparado

e simplesmente sair e fazer isso. Eu acho que nós dois sabemos que podemos retirá-la. Você sabe que nos sentimos confortáveis o suficiente para isso, temos experiência suficiente. $\mathrm{E}$ a emoção disso! Eu gosto muito dessa maneira de realizar também! Onde há pouco ou nada decidido, e simplesmente ir lá e fazer isso. E eu sinto que eu, também como Ray, muitas vezes, eu sinto que isso é ... como posso dizer ... surge em alguma parte de mim que ... isso desperta algo em mim, de alguma forma, para fazer nenhuma decisão, e para mergulhar ali. Isso é muito excitante para mim!

Suzi Weber - Isto faz parte da performance. Em relação à dança, ao campo da dança, como fica essa ideia da performance. Vocês trabalham entre a dança e a performance, é isto? Há uma diferença entre a performance e a dança? Qual é a parte da dança e qual a parte da performance? Eu sei que há...

$\mathrm{AH}$ - Ah, o que parte é a dança, e que parte é performance? Você sabe, como você separar? mance?

Suzi Weber - Correr o risco, talvez...O que está mais perto da perfor-

RC - Bem, eu poderia cozinhar meu café da manhã como uma performance. (risos) Quero dizer ...

$\mathrm{AH}$ - (risos) Você poderia cozinhar meu café da manhã como uma boa performance! (risos)

RC - Sim , ir ao toilette como uma performance! ( risos ) Mas , para mim, é mais, não é tão

importante, na verdade, o que é que eu estou fazendo, mas é mais como eu estou fazendo isso. Se há uma clara presença, clareza de intenção, se esse é o meu objectivo na performance, de qualquer maneira. Quero dizer, eu fui a performances onde tudo é apenas uma espécie de confusão e não está muito claro o que está acontecendo, mas essa era a intenção daquilo.

Mas então, quando você pergunta sobre dança, eu tenho que dizer, o que você quer dizer com dança? Porque, é apenas qualquer tipo de movimento, ou é o movimento em uma linguagem específica de movimento? Estou supondo que você queria dizer qualquer tipo de movimento, porque ... essa é a mais ... veis?

$\mathrm{AH}$ - Você generaliza quando dizes dança, queres dizer em todos os ní-

Suzi Weber - Sim. Eu penso no campo da dança, no campo funcional da dança. A dança como espetáculo.

$\mathrm{AH}$ - O meio profissional. 
Suzi Weber - O meio, o métier.

$\mathrm{AH}$ - O Métier. A profissão de dança. Bem, é interessante, sabe, a profissão de dança, porque mais uma vez, somos improvisadores profissionais, e isso é um meio específico dentro da dança.

$\mathrm{RC}$ - Muito pequeno!

$\mathrm{AH}$ - A dança é o meio, é o universo, e a improvisação é um país pequeno pouco dentro do universo da dança. E não é grande em comparação com a dança. Você sabe, se você olhar para o mundo clássico, se você olhar para a dança moderna, a dança folclórica, as danças étnicas, talvez existam há séculos! Há muito tempo, muita história. Você tem dança nas boates, onde as pessoas vão dançar música disco, que é a dança também. E é diferente. Chris Aiken, que é um grande amigo nosso, quando ele era jovem, ele ia muito às boates. Eu também. Mas foi muito importante para Chris ir para as boates e dançar. E se soltar, botar para fora, você sabe, e estar numa situação onde todos estão numa espécie de mente em comum, onde as pessoas vão lá porque querem se soltar, querem se expressar, e estar em uma cena, uma situação em que outras pessoas estão fazendo um tipo de coisa semelhante. A improvisação é apenas um particular, um ramo muito particular de dança. Mas mais ainda, eu diria, não é um particular, a improvisação não é um ramo particular de dança. A improvisação é um ramo particular de interesse e de expressão, eu diria. Porque há improvisadores em todos os tipos de categorias.

Há contadores de histórias que são improvisadores, existem músicos que são improvisadores, existem poetas, há ... Você sabe, não é apenas dança ...

RC - Teatro.

$\mathrm{AH}$ - Teatro. Há pessoas no mundo que estão interessados, em todos os lugares, há pequenos redutos de pessoas que estão interessados em uma abordagem mais espontânea à arte, à criação de arte, em fazer arte. E a arte é uma coisa viva. E não se trata de gastar um monte de tempo, muito estudo e muita reflexão, muita perfeição, muito polimento de alguma coisa, para chegar a alguma coisa. É completamente a sua outra extremidade do espectro. E como usar a matéria-prima que vem à superfície, e sendo astuto, sendo artístico com aquela matéria crua, de imediato. Imediatamente! E ser capaz de formar algo a partir do nada, muito rapidamente, e lá está!

RC - Me parece que uma coisa que talvez não se mencione tanto no mundo mais amplo da dança é que cada um usa a improvisação em algum momento de seu processo. Mas é apenas na performance que esta pequena parte existe. Mas ela está lá , e eu acredito que as pessoas não lhe dão o crédito que ela realmente precisa ou merece. Isso faz muito mais da parte do processo criativo ...

$\mathrm{AH}$ - Bem, na dança. Porque eu descordo se estamos falando de música. Porque no jazz, você sabe, a improvisação na música é totalmente aceita agora, e há grandes nomes, e milhares de pessoas vão a La Place des Arts ver Oscar Peterson tocar, que é um pianista de jazz fenomenal, e ele improvisa! E ele passou toda sua vida improvisando, e as pessoas pagam cinqüenta, sessenta, setenta dólares para ir vê-lo improvisar. Mas há muito mais história nisso. 
Suzi Weber - Há uma tradição?

$\mathrm{AH}$ - Sim, sim, há uma tradição.

Suzi Weber - É mais antiga, talvez?

$\mathrm{AH}$ - É. E nós estamos chegando nessa tradição com a dança agora. Está realmente apenas começando depois de 50 anos. Cinqüenta anos de improvisação em dança. Então, é de meados da década de cinquenta,quando começou a entrar em jogo. Assim, é relativamente jovem, ainda. E o Contato é ainda mais jovem! Contato tem trinta, trinta e cinco anos de idade.

RC - Mas também, o público para a música, em geral, eu acho que é mais amplo do que o público para a dança.

$\mathrm{AH}$ - Para dança, sim, é verdade também. Há um público muito maior para a música de que para a dança, em geral. E eu diria, até mesmo para o teatro. Há um público bem maior para o teatro do que existe para a dança também, eu diria.

Suzi Weber -Mas se deve ser espontânea, improvisada, espontânea, como contornar essa questão de eficácia dos corpos, esse modelo de corpo tão forte em dança?

$\mathrm{AH}$ - Então, como é que vamos além dos modelos padronizados de dança? O que fazemos?

RC - Hum ... Bem, essa é a minha opinião sobre isso. Especialmente com a improvisação, o processo que estamos passando, o que está na performance, é o produto . Porque o que temos para oferecer é diferente a cada vez. Então é isso que estamos oferecendo. É o processo de comunicar, de criar, de compor, de se relacionar, de se expressar. Eu acho que é uma parte de se comunicar. E, com a improvisação, você sabe, nada é garantido, então ... E esse é o risco que corremos sempre. Porque eu estive em peças que não eram tão boas, e eu não me sentia tão bem. Então eu sinto que o que estamos oferecendo nas performances, pelo menos é o processo. Nas aulas ... para mim, de qualquer maneira, é aprender a aprender. Porque, como estudante, se eu estou atento ao meu processo, a como eu estou fazendo isso, eu posso continuar a fazer isso fora da aula, e continuar a aprender. Mas se eu estou apenas praticando os movimentos, isso é tudo o que eu vou fazer fora da aula. Será que isso faz sentido?

$\mathrm{AH}$ - Além disso, eu gostaria de acrescentar que, se usarmos o modelo padrão da dança em performance, e o coreógrafo como algo que ele quer passar. Geralmente, ele tem uma boa idéia sobre o que quer, e ele usa suas próprias ferramentas para transmitir ao público algo, e para entreter o público, de uma certa maneira também. Eu acho que com a improvisação é diferente porque ela envolve mais o público de alguma maneira. Então, é mais ... se eu posso usar a palavra diálogo, em um certo nível, com o público, porque o público tem uma certa responsabilidade de fazer sentido, para tirar partido da sua própria experiência, e ver o que está acontecendo no espetáculo, e fazer algum sentido do que está acontecendo. E assim, nós não estamos apenas entregando em uma bandeja. Você sabe, isso é o que é, e isso vai ficar 
assim, e tem essa estética, e isso deve tocar certos botões em você, e despertar um certo tipo de sentido de consciência, ou dever frente ao que acontece politicamente ou socialmente no mundo, ou isso ou aquilo. Tudo isso está bem, é bom. Mas, com a improvisação é diferente porque nós não sabemos o que a coisa final vai ser. Nós não sabemos depois de uma hora o que é, naquele momento do tempo, ou como ela vai afetar o público. E isso não vai afetar qualquer pessoa de forma diferente, e não é, não há um padrão que estamos trabalhando. E nesse sentido, eu acho que o público tem um tipo diferente de responsabilidade. Eles são colocados em uma posição diferente. E não é fácil, às vezes. Não é fácil. Não é, você não está apenas entrando numa improvisação para ser entretido. Não é apenas sobre entretenimento. É também sobre algo além da comunicação, é ter de encontrar com o que você vê e se colocar ali, ao invés de apenas sentar complacentemente e, talvez, apreciar o processo. Então, para mim, varia muito, o diálogo que você tem com o público é bem diferente. Eu me sinto muito diferente quando eu faço o trabalho improvisado frente a um público, do que quando faço um trabalho definido. É bem diferente, e o que você está tentando transmitir é diferente, e como você se sente por dentro, também é. É um trabalho duro, muitas vezes é bastante abstrato o que está acontecendo, e a performance pode ser bastante abstrata, como outras formas de dança podem ser muito abstratas. É bonito, há forma, não há forma, há energia, há conexões em andamento, mas muitas vezes eu acho que público quer classificar, há uma necessidade do cérebro em compreender. Você sabe, esse é o trabalho do nosso cérebro, entender o sentido das coisas, "Eu quero entender o que está acontecendo". Assim, o cérebro está trabalhando para entender, e quando você improvisa você não está colocando todas as peças de uma forma cognitiva muito racional. Eles são como vinhetas, ou como coisas que aparecem e desaparecem e, com base em sua própria história e suas próprias experiências , e, o que você sente que está acontecendo na performance, você vai dar sentido àquilo: você gosta, você não gosta daquilo.

Ele faz amor naquela parte e eu odiei, você sabe, as pessoas sentem de forma diferente. Mas o principal são aquelas coisas: é vivo, é ao vivo. Isso, para mim, é a principal diferença. É uma coisa viva, que todos, não apenas os artistas, mas os artistas, o público, todo mundo que está naquele espaço naquela noite, estamos no mesmo lugar, assistindo algo que está sendo feito agora, na frente de todos nós. E isso é bem diferente do que ver algo que foi trabalhado por um longo tempo. Então, como disse Ray, você assistindo a um processo, e isso é o que está sendo oferecido; você não está assistindo a um produto final. Dito isto, a improvisação pode ser trabalhada, de antemão, e você pode ter algumas idéias, ou alguns conceitos, ou algo que você queira comunicar. Você pode ter criado um ambiente inteiro, e um espaço, através de cenários, luzes, música, de forma a afetar o que você está fazendo de uma certa maneira, sem, talvez, verificar tudo. Possui, porém, uma cor, uma textura, um sabor. Qualquer tipo de decisão vai ter alguma influência sobre o processo. Você pode colocar alguma coisa no espaço, e você pode lá. Se ele é usado ou não. $E$, às vezes, o fato de que ele não é usado pode ser a coisa mais 
agradável, em vez de usar algo que poderia ser. Talvez esse objeto colocado no espaço nunca seja usado ou, talvez, ele seja usado em demasia, e é como se já fosse o suficiente , então ...

Suzi Weber - Ok. Obrigada. Merci ! 